\title{
Endoscopic management of periventricular and intraventricular arachnoid cysts
}

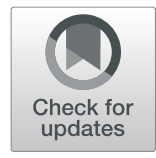

\author{
Ahmed Abdel Aziz Fayed", Tamer Ibrahim and Tarek Rayan
}

\begin{abstract}
Introduction: The most successful surgical management of periventricular and intraventricular cysts is still a matter of debate. Up to the early 1990s, open cyst fenestration and cystoperitoneal shunts were the only options available. Recently, different endoscopic approaches to these lesions have gained popularity.

Methods: Eighteen endoscopic procedures were performed for the treatment of arachnoid cysts in 18 patients. Sylvian fissure arachnoid cysts were excluded from this study. Ten of them were females and eight were males with their ages ranging from 6 months to 50 years with a mean of 16 years. All patients were prospectively observed.

Results: Seven of the arachnoid cysts were in the suprasellar region, 5 in the quadrigeminal region, 2 in the posterior fossa, 2 parietal, and 2 intraventricular. Seventeen cases (94\%) had hydrocephalus. The main presenting manifestations were those of increased intracranial pressure. All fenestrations were done in the lateral ventricle except for the 2 cases with posterior fossa arachnoid cysts, the fenestrations were done to the fourth ventricle. Endoscopic ventriculocytostomies (VC) were performed in 14 cases without operative complications and no stents were placed. Endoscopic cystocisternostomies (C) were done in all suprasellar cases. Endoscopic cystoventriculostomies (CV) were done in 4 cases. The mean surgical time was $1 \mathrm{~h}$. The mean follow-up period was 15 months. Symptoms improved in 17 cases. Seventeen cases demonstrated a significant decrease of the cysts' size in the postoperative computed tomography (CT) and magnetic resonance imaging (MRI). A single case developed a complication in the form of subdural hygroma which required no intervention and was managed conservatively.

Conclusion: Endoscopic management of periventricular and intraventricular arachnoid cysts is a useful safe option in the management of arachnoid cysts related to the ventricular system.
\end{abstract}

Keywords: Periventricular and intraventricular cysts, Arachnoid cysts, Endoscopic approaches

\section{Introduction}

Arachnoid cysts are cerebrospinal fluid (CSF)-containing lesions located intraarachnoidal and have no communication with the ventricular system; they represent approximately $1 \%$ of lesions of the intracranial fossa. They are considered as developmental anomalies, due to their prevalence in children [1], although the intraventricular type of arachnoid cysts is rare forming only $0.3 \%$ of arachnoid cysts in children [2].

The exact mechanisms of their development are still unclear. The majority are congenital, but they can also develop secondary to neurological insults such as head

\footnotetext{
*Correspondence: Dr.ahmadfayed@gmail.com

Neurosurgery Department, Faculty of Medicine, Alexandria University, Alexandria, Egypt
}

injuries, meningitis, hemorrhage, tumors, or postoperatively $[2,3]$.

Theories of their congenital origin are still controversial; the most accepted include cerebral lobe agenesis and fluid hypersecretion by the lining cells of the cyst wall, which may explain why certain cysts increase gradually in size [4], while the long-term behavior of these cysts is still not well understood [5-7].

Intraventricular cysts are most commonly located at the temporobasal (34\%), suprasellar (21\%), cisterna quadrigemina (18\%), paraxial supratentorial $(16 \%)$, and other various $(10 \%)$ regions $[8,9]$.

Andre classified suprasellar arachnoid cysts (SAC) into SAC-1 due to the expansion of the diencephalic leaf of

\section{Springer Open}

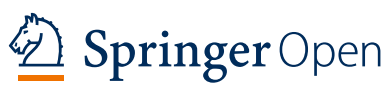

(c) The Author(s). 2021 Open Access This article is licensed under a Creative Commons Attribution 4.0 International License, which permits use, sharing, adaptation, distribution and reproduction in any medium or format, as long as you give appropriate credit to the original author(s) and the source, provide a link to the Creative Commons licence, and indicate if changes were made. The images or other third party material in this article are included in the article's Creative Commons licence, unless indicated otherwise in a credit line to the material. If material is not included in the article's Creative Commons licence and your intended use is not permitted by statutory regulation or exceeds the permitted use, you will need to obtain permission directly from the copyright holder. To view a copy of this licence, visit http://creativecommons.org/licenses/by/4.0/. 
the Liliequist membrane, SAC-2 due to the expansion of the interpeduncular cistern with a defect of the mesencephalic part of Liliequist membrane, and SAC-3 include asymmetrical forms with SAC at other subarachnoid spaces [10].

Histopathologically, they are arachnoid connective tissue and appear to form from the splitting of the arachnoid membrane, with an inner and outer membrane around the cyst cavity, without epithelial lining or vasculature. They should be differentiated from glioependymal cysts, which have epithelial lining and are of neuroectodermal origin, especially when lying at the supracollicular or retrocerebellar regions [2].

Arachnoid cysts are sometimes clinically silent, incidentally diagnosed as a result of the widespread use of imaging studies $[5,11-13]$, and are usually managed conservatively. Symptomatic arachnoid cysts can present with a wide spectrum of clinical manifestations including those of increased intracranial pressure [2], developmental delay in younger children, visual loss and precocious puberty when occurring at the suprasellar cistern, or seizures and focal neurological deficits when cortically centered [1]. These symptomatic cysts often necessitate treatment $[2,14]$.

Surgical modalities in treatment of arachnoid cysts still remain controversial [15]. In the past, they have been treated successfully by stereotactic aspiration [9], CSF shunting, or open craniotomy for cyst fenestration. Although often successful, permanent shunts and craniotomies have their morbidities and complications. Reports of endoscopic cyst fenestration were rare $[1,16]$. Nowadays, they are increasing, as endoscopy is simple, effective, minimally invasive, and association with low rates of morbidity and mortality $[15,17]$.

Different endoscopic procedures and approaches are available and are sometimes controversial depending on the site of the cysts and their relation to the ventricular system or nearby cisterns. In symptomatic arachnoid cysts located outside, the ventricle fenestration into the basal cisterns is the gold standard [18]. However, when this is not feasible, the goal of the surgery is to perform a connection between the cyst and the ventricular system [18].

Both endoscopic procedures used in SACs, ventriculocystostomy (VC) and ventriculocystocisternostomy $(\mathrm{VC}+\mathrm{C})$, are still controversial. Nevertheless, due to the statistically significant difference between the incidence of recurrence on long-term follow-up, after $\mathrm{VC}$ versus $\mathrm{VC}+\mathrm{C}, \mathrm{El}$ Ghandour concludes that $\mathrm{VC}+\mathrm{C}$ should be considered as the procedure of choice in the treatment of SACs [17].

For quadrigeminal cysts, different endoscopic approaches and procedures have been applied including cyst fenestration and removal through a suboccipital supracerebellar approach or opening it through lateral ventricle-cystostomy and third ventricle-cystostomy [19]. Endoscopic cystoventriculostomy represents a useful management option for patients with paraxial arachnoid cysts in whom a standard cystocisternotomy is not feasible [18].

It is sometimes advisable to add endoscopic third ventriculostomy in order to solve the associated hydrocephalus while managing these cysts [16].

\section{Patients and methods}

Eighteen endoscopic procedures were performed for the management of the periventricular and intraventricular arachnoid cysts in 18 patients. All patients were prospectively observed.

The endoscopic procedures were performed at our institution for intra- and periventricular cystic lesions between January 2016 and December 2017. Informed consent was obtained from all patients. The ethical committee of the Faculty of Medicine, Alexandria University approved the study. Sylvian fissure arachnoid cysts were excluded. All patients underwent preoperative cerebral magnetic resonance imaging (MRI). CSF flowmetric studies were done in 3 cases preoperatively. The neuroendoscopic procedures were performed with a 0 degree rigid endoscope (Storz Gaab). The surgical plan and best trajectory were selected on preoperative MRI; a free-hand procedure without neuronavigation was performed. The ventricle or the cyst was tapped based on the selected procedure through a frontal or parietal burr hole or posterior fossa burr hole. After a careful inspection of the cyst surface, the cyst wall was perforated using a monopolar diathermy under continuous irrigation (Fig. 1), a progressive dilatation of the fenestration site was performed using a $3 \mathrm{~F}$ Fogarty balloon (Fig. 2)

The endoscope was then introduced within the fenestrated wall to exclude the presence of septa inside the cyst.

Endoscopic procedures were done in the form of:

- Ventriculocystostomy (VC): the ventricle was entered first, then the cyst was identified and a fenestration was applied to the cyst wall (Fig. 3).

- Cystoventriculostomy (CV): the cyst was entered first, its interior was examined to find the ventricle, and a fenestration was applied between the cyst and the ventricle (Fig. 4).

- Cystocisternostomy $(\mathrm{C})$ : the cyst was opened into nearby cisterns.

- Third ventriculostomy (ETV): was added to different procedures to treat associated hydrocephalus.

Postoperatively, all patients underwent computed tomography $(\mathrm{CT})$ scans within the first $24 \mathrm{~h}$ after surgery 


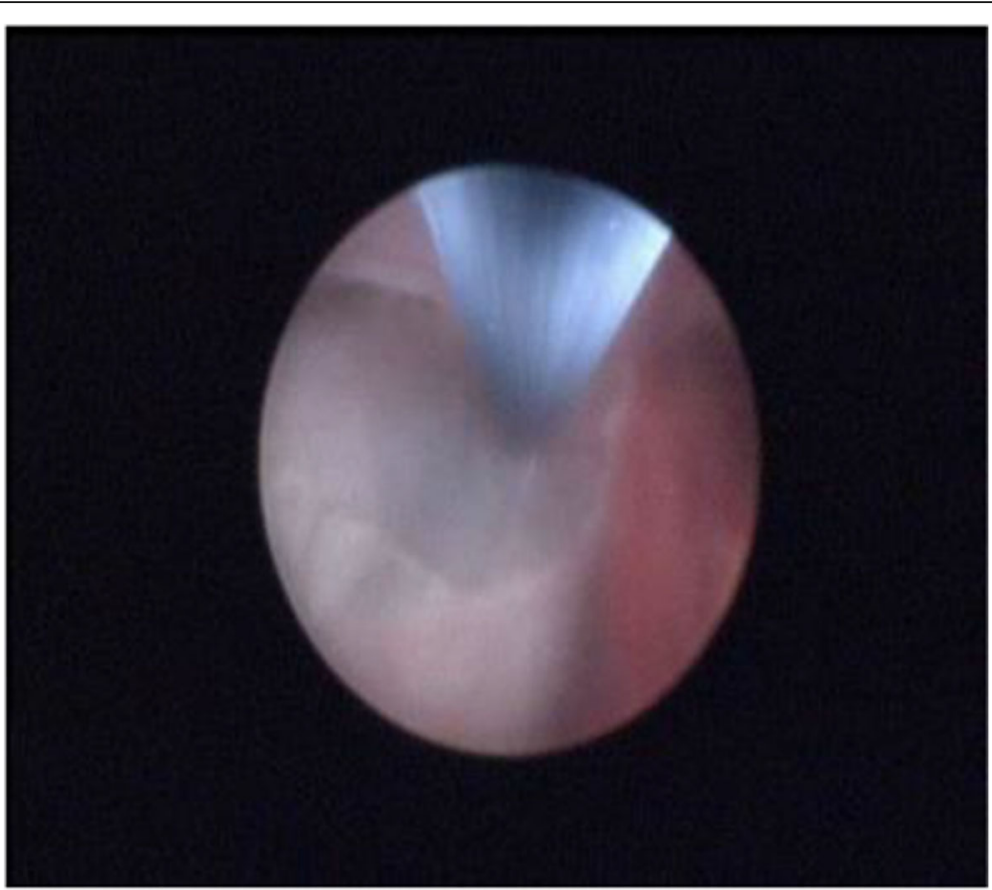

Fig. 1 Endoscopic view showing opening the dome of the cyst

and MRI control 3 months after surgery. MRI CSF flowmetric studies were done postoperatively in a single case. Clinical outcome was described as improved (defined as partial or complete relief of symptoms), same, or deteriorated state (defined as progression of clinical symptoms). Radiological outcome was described regarding the size of the cyst whether decreased, same, or increased.

\section{Results}

Eighteen endoscopic procedures were performed for the management of the periventricular and intraventricular arachnoid cysts in 18 patients. Ten of them were females (55\%) and eight were males (45\%) with their ages ranging from 6 months to 50 years with a mean of 16 years old. All patients were prospectively observed.

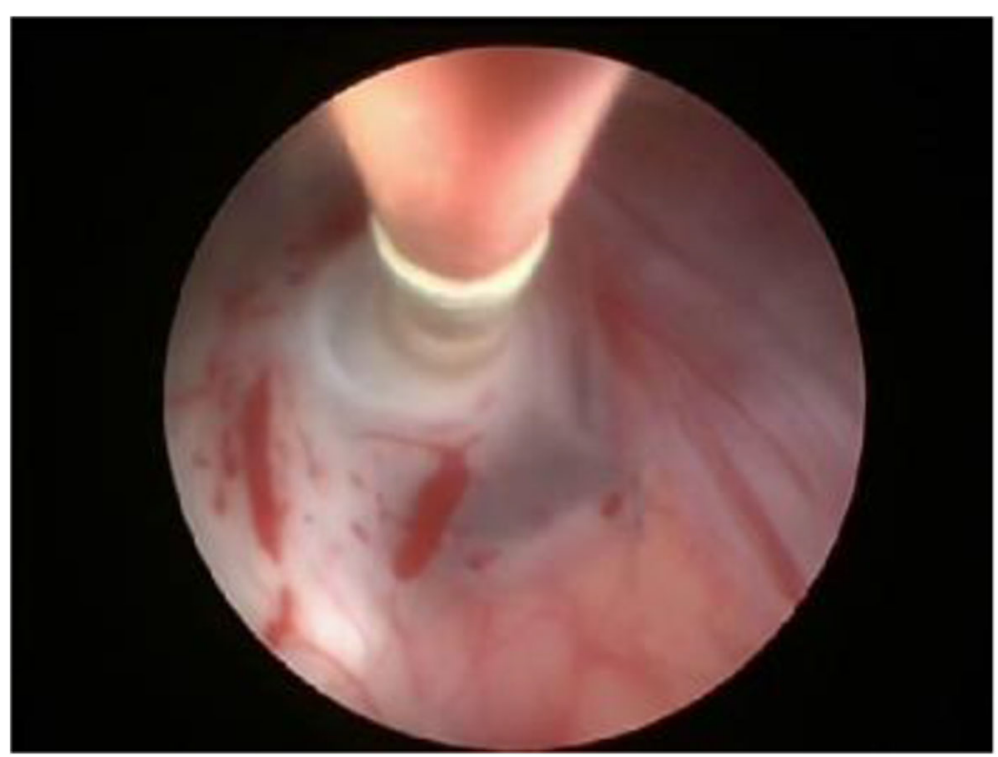

Fig. 2 Endoscopic view showing widening of a fenestration with Fogarty catheter 


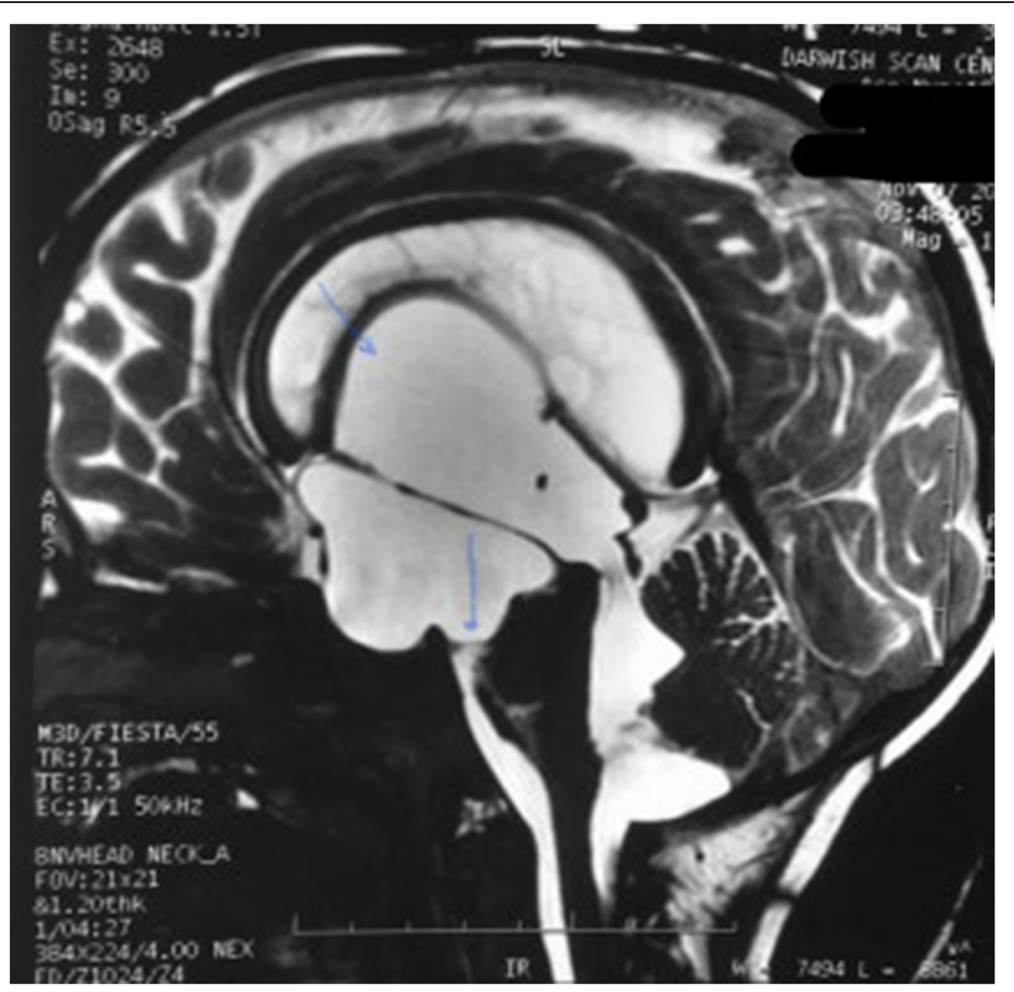

Fig. 3 MRI T2 sagittal sequence with an arrow identifying the site of ventriculocystostomy and cystocisternostomy

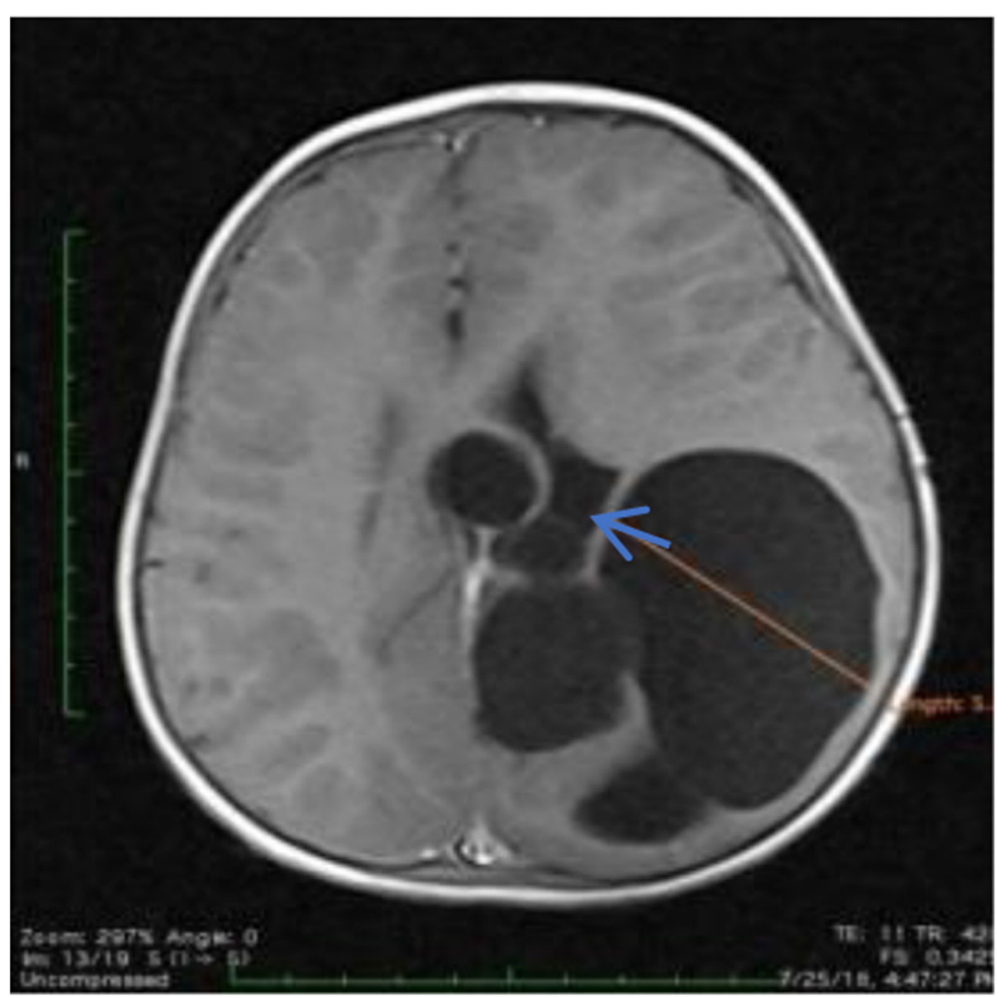

Fig. $4 \mathrm{MRI}$ T1 axial sequence with an arrow showing the site of cystoventriculostomy 
Seven of the arachnoid cysts (39\%) were in the suprasellar region, 5 in the quadrigeminal region $(28 \%), 2$ in the posterior fossa (11\%), 2 parietal (11\%), and 2 intraventricular (11\%). Seventeen cases $(94 \%)$ had hydrocephalus. The main presenting manifestations were those of increased intracranial pressure. All fenestrations were done to the lateral ventricle except for the 2 cases with posterior fossa arachnoid cysts; (11\%) the fenestrations were done to the fourth ventricle.

Endoscopic ventriculocystostomy was performed in 14 cases $(78 \%)$ including 7 suprasellar cysts, 5 quadrigeminal cysts, and 2 intraventricular arachnoid cysts (Figs. 3 and 5). The lateral ventricle was entered in 14 cases $(78 \%)$ with a free-hand technique through the classical Kocher's frontal burr hole. The suprasellar arachnoid cysts were bulging through the foramen of monro, and the quadrigeminal cysts were reached through the body of the ventricle (Fig. 6)

Endoscopic cystocisternostomy was done in 7 cases (39\%) (Fig. 3). All of them were suprasellar arachnoid cysts in which the floor of the cyst was inspected and was opened into the surrounding cisterns to ensure cyst decompression.

Endoscopic cystoventriculostomy was done in 4 cases (22\%) including the posterior fossa cysts and the parietal paraxial supratentorial cysts (Figs. 7 and 8) The cyst was entered using a free-hand technique through a parietal burr hole in the para-axial parietal arachnoid cysts and a posterior fossa burr hole for the posterior fossa cysts (Fig. 7). The interior of the cyst was explored in order to identify the lateral and the fourth ventricular cavities in the parietal and posterior fossa cysts, respectively.

Endoscopic third ventriculostomy was done in a single case $(5 \%)$. The mean surgical time was $1 \mathrm{~h}$. No operative complications were reported and no stents were placed. The mean follow-up period was 15 months. Manifestations improved in 17 cases (94\%). Seventeen cases demonstrated a significant decrease of the cysts' size on the follow-up MRI with improvement in the associated hydrocephalus.

No cases needed shunt application during the postoperative or follow-up periods. A single case developed a complication in the form of subdural hygroma (5\%), which required no intervention and was managed conservatively. This case was a quadrigeminal cyst which was managed with VC and ETV (Fig. 9).

\section{Discussion}

The surgical management of arachnoid cysts includes various techniques as open craniotomy and cyst resection, cystoperitoneal shunting, and others. Recently, the advantages and disadvantages of endoscopy have been described in the literature [8].

In this study, 18 cases with arachnoid cysts were treated with different endoscopic techniques; Sylvian fissure arachnoid cysts were excluded, as they have the lowest success rate and the highest complication rates when managed endoscopically. Ortel found only 52\% radiological success rate in Sylvian fissure cysts treated

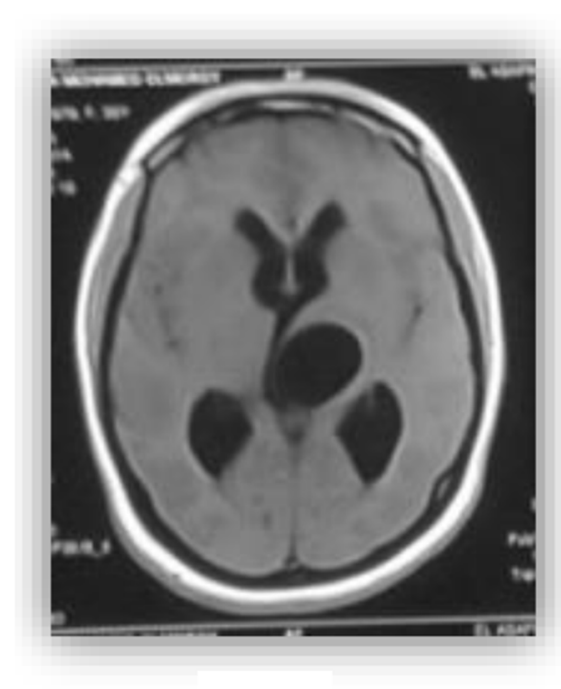

(a)

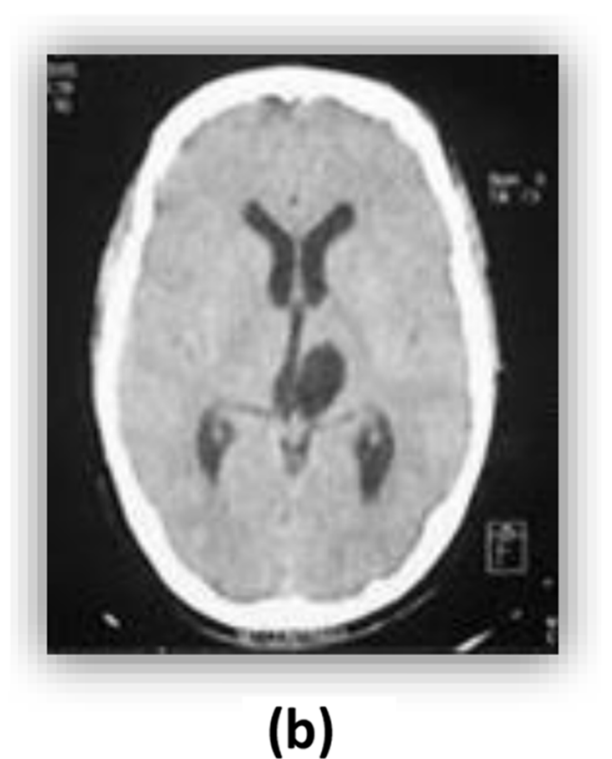

Fig. 5 a MRI T1 axial sequence showing left quadrigeminal cyst in 45 y old female patient. b Follow-up CT brain after 1 month postoperatively showing reduction of the cyst size. The procedure applied was endoscopic ventriculocystostomy through left frontal burr hole and left lateral ventriculocystostomy 


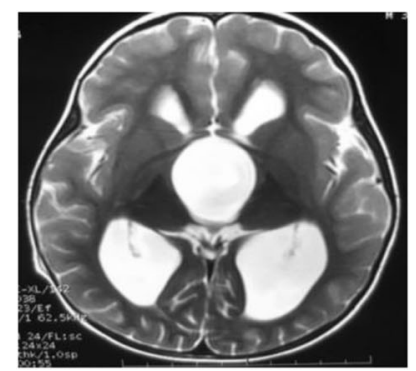

(a)

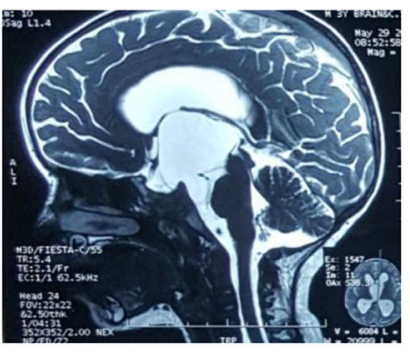

(b)

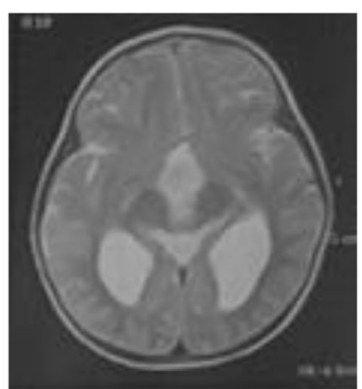

(c)

Fig. 6 a MRI T2 axial sequence showing suprasellar arachnoid cyst bulging inside the third ventricle in a 3-year-old male. b MRI T2 sagittal sequence showing suprasellar arachnoid cyst bulging through the foramen of monro. c Follow-up MRI T2 sequence after 3 months postoperatively showing reduction of the cyst size. The procedure applied was endoscopic ventriculocystostomy and cystocisternostomy through the right frontal burr hole

endoscopically; Choi has a $60 \%$ success rate while Karabatso and Pardilla have $9 \%$ and $27 \%$ success rates, respectively. Although the clinical success rates were much better in these studies, the failure of regression in size was significant and raised the possibility of the recurrence of manifestation on long-term follow-up [8].

The most common types of arachnoid cysts in this study were the suprasellar arachnoid cysts ( 7 cases) followed by the quadrigeminal cysts (5 cases). The endoscopic technique applied differed according to the site of the cyst.

Regarding Suprasellar arachnoid cysts, different studies described different endoscopic techniques including endoscopic $\mathrm{VC}$ alone or combined endoscopic $\mathrm{VC}+\mathrm{C}$. In this study, we performed combined $\mathrm{VC}+\mathrm{C}$, which is consistent with El Ghandour [17] who concluded that $\mathrm{VC}+\mathrm{C}$ is the treatment of choice in these cases [17].

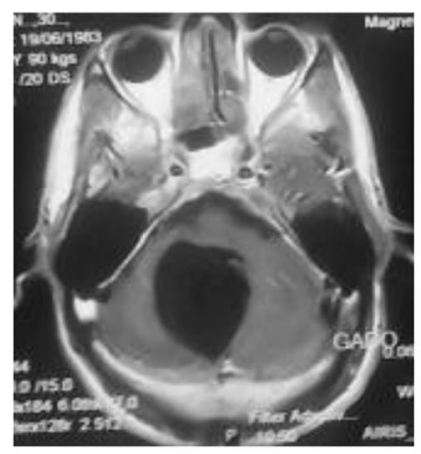

(a)

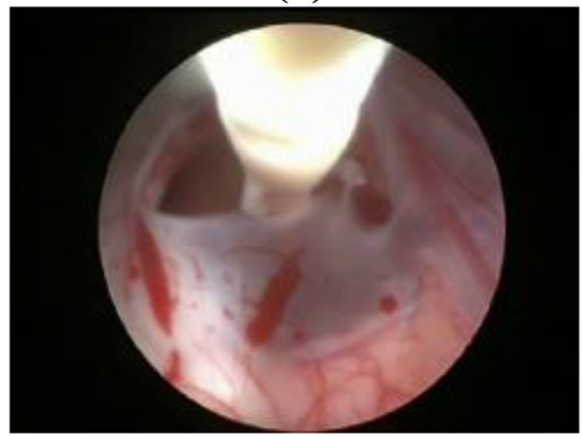

(c)

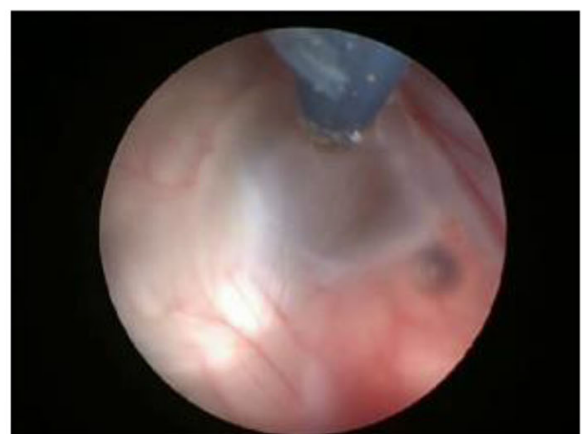

(b)

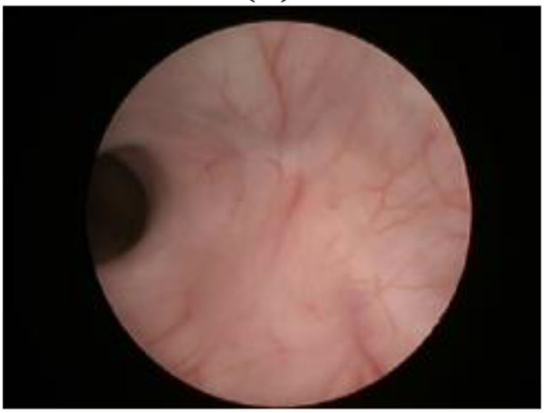

(d)

Fig. 7 a MRI T1 axial sequence with contrast showing posterior fossa cyst related to the fourth ventricle and compressing it. b Endoscopic view showing identification of the fourth ventricular wall from inside the cyst and performing endoscopic cystoventriculostomy. c Applying a fenestration between the cyst and the ventricle with a Fogarty catheter. $\mathbf{d}$ Endoscopic navigation inside the fourth ventricle with identification of the aqueduct of Sylvius 


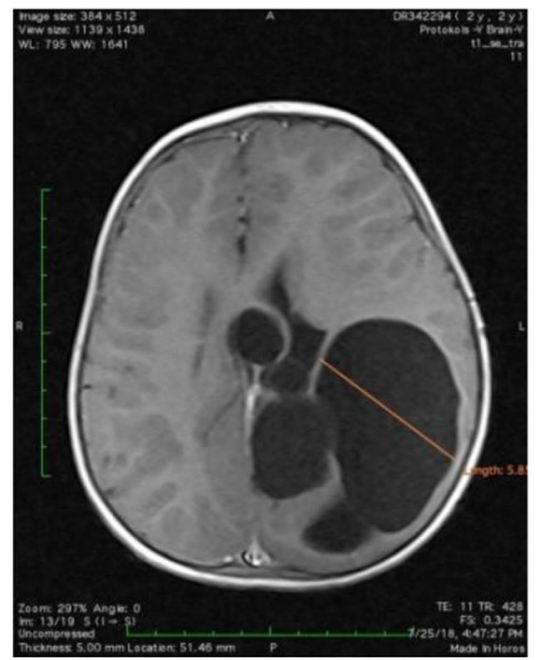

(a)

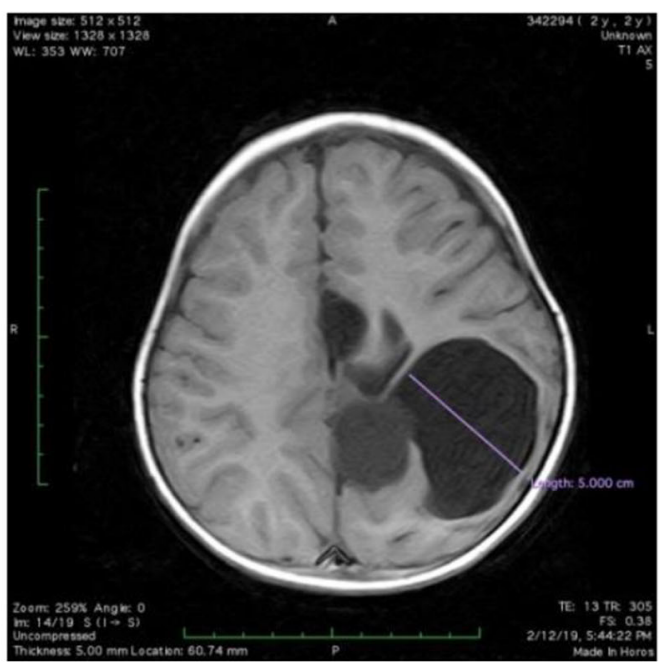

(b)

Fig. 8 a MRI T1 axial sequence showing left parietal paraxial arachnoid cyst effacing the lateral ventricle in a 1-year-old female. b MRI T1 axial sequence showing a decrease of the size of the cyst after 1-year follow-up. The procedure applied was endoscopic cystoventriculostomy through the left parietal burr hole

Applying endoscopic $\mathrm{VC}+\mathrm{C}$ to all suprasellar cases in this study allowed the decrease of the cyst s size in $100 \%$ of cases and control of manifestations in $85 \%$ of cases.

In Quadrigeminal cysts, three different endoscopic approaches and procedures were described in the literature, including cyst fenestration and removal through a suboccipital supracerebellar approach, lateral VC, and third ventricle-cystostomy [19]. In a study published by Gangemi, the most commonly used approach was the lateral VC approach [19]. In this study, the lateral VC technique was performed for all 5 cases, as they were all huge in size and bulging inside the lateral ventricle. Fenestration was established through the floor of the body of the lateral ventricle. The role of added ETV in these cases in order to treat the associated hydrocephalus is questionable. It is not easy to conclude whether an added ETV is mandatory or the cyst fenestration with recanalization of the aqueduct is usually enough for clinical improvement? [19].

In a single case in this study, VC and endoscopic ETV were performed as there was associated marked hydrocephalus. Unfortunately, this case developed subdural hygroma that was managed conservatively and showed spontaneous resolution over 3 months. Overtreatment in targeting the cyst and the associated hydrocephalus may have been the result of this complication.

In two cases of intraventricular cysts in this study, the $\mathrm{VC}$ technique was performed safely.

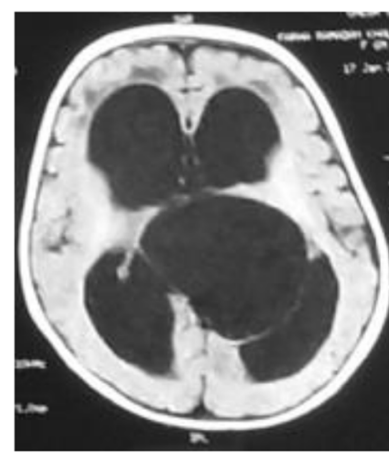

(a)

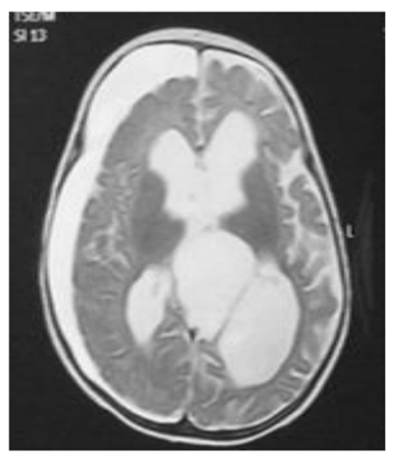

(b)

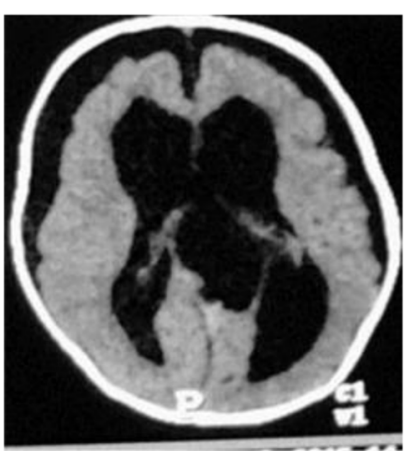

(c)

Fig. 9 a MRI T1 axial sequence showing quadrigeminal arachnoid cyst bulging inside the lateral ventricle in a 6-month-old male. b MRI T2 axial sequence after 1 month showing marked decrease in the size of the cyst and resolution of hydrocephalus with development of chronic subdural hygroma after performing endoscopic ventriculocystostomy and third ventriculostomy. c Follow-up $\subset$ after 3 months postoperatively showing reduction of the size of chronic subdural hygroma without intervention 
In parietal supratentorial paraxial cysts and posterior fossa cysts, CV was performed, and they were opened directly to the ventricular system with free hands in the absence of neuronavigation. This is contrary to Ortel [8] who recommended neuronavigation to facilitate the entry from the cyst to the ventricle. In all 4 cases in this study, it was easy to identify the underlying ventricular cavity through the cyst wall knowing it by its transparency. Also, the absence of thick brain parenchyma facilitated the procedure without neuronavigation. Although these cysts were close to the cortical surface, none of these cases was complicated with CSF fistula.

Regarding complications, we have a single case that developed subdural hygroma (5.5\%) and was managed conservatively; Copley [2], in his study with a larger number of cases, had a complication rate of $20 \%$ but all of them as he mentioned were treated easily without subsequent morbidity and mortality. El Ghandour [17], in his series, had a single case of subdural hygroma (4\%), single case of hemorrhage (4\%), and a single case of CSF leakage $(4 \%)$. These complications were the most frequent complications reported in literature; however, the risk of seizures and deficits were extremely rare [2].

Clinical improvement was found in $94 \%$ of the cases, only one case showed no improvement in the clinical manifestations despite the decrease in the cyst size, and this could be explained by the short period of follow-up (6 months).

The cysts' size decreased in $94 \%$ of the cases; only one posterior fossa case remained the same size on follow-up although improvement of the clinical manifestation was stated, supporting the hypothesis that claims that the manifestations are mainly due to the pressure effect rather than the size of the cyst. This needs further research involving a larger sample size and longer followup periods to prove such theory.

In the present study, none of the cases showed recurrences nor increased in the size of the cysts; however, the follow-up period is short and requires longer followup to document the patency of the established stoma. On the opposite side, Copley [2] declared that $41 \%$ of children in his study required revision surgery at a certain time due to symptom recurrence and that his results are consistent with literature that announced the need for further surgery, including shunt insertion, following endoscopic fenestration and that the studies reporting a $100 \%$ success rate following a single endoscopic procedure were typically limited by smaller patient numbers and/or shorter follow-up periods.

No stents were used in this study to maintain the patency of the stoma, which is in agreement with Ortel [18] who showed evidence that even a small stoma without stent insertion might be sufficient for adequate cyst drainage, in contrary to previous reports denoting the importance of the size of cyst fenestration and stent insertion for avoidance of cyst recurrence [20]. However, this suggestion needs well-designed studies with longer follow-up period to prove its validity.

\section{Conclusion}

The present study reports successful treatment of arachnoid cysts by various endoscopic techniques which are safe options for the management of periventricular and intraventricular arachnoid cysts. Endoscopic ventriculocystostomy and cystocisternostomy are considered for suprasellar arachnoid cysts while ventriculocystostomy for intraventricular cysts and cystoventriculostomy are the procedure of choice for paraxial non cisternal symptomatic arachnoid cyst and posterior fossa cysts. The technique should be preferred to the placement of a cystoventricular or cystoperitoneal shunt. However, longer follow-up is required before definite conclusions can be drawn regarding cyst recurrences.

\section{Abbreviations}

SAC: Suprasellar arachnoid cysts; CSF: Cerebrospinal fluid; MR: Magnetic resonance; VC: Ventriculocystostomy; VC+C: Ventriculocystostomy + cystocisternostomy; ETV: Endoscopic third ventriculostomy:

CV: Cystoventriculostomy

\section{Acknowledgements \\ Special thanks to the medical team and patients.}

\section{Authors' contributions}

The authors described their own experience as main surgeons regarding the endoscopic management of periventricular and intraventricular arachnoid cysts. The authors read and approved the final manuscript.

\section{Funding}

No funding was available.

Availability of data and materials

The datasets used and/or analyzed during the current study are available from the corresponding author on reasonable request.

\section{Declarations}

Ethics approval and consent to participate

Ethical approval was obtained from the ethics committee, faculty of medicine Alexandria university. Consent for participation in the current study was obtained from all participants, 5 were adults and a direct consent was obtained from them and 13 were children under 18 years of age and consent was obtained from their parents.

Consent for publication

Not applicable.

\section{Competing interests}

The authors declare that they have no competing interests

Received: 6 May 2019 Accepted: 24 May 2021

Published online: 13 September 2021

\section{References}

1. Greenfield JP, Souweidane MM. Endoscopic management of intracranial cysts. Neurosurg Focus. 2005;19(6):E7. https://doi.org/10.3171/foc.2005.19.6.8.

2. Copley P, Kirkman MA, Thompson D, James G, Aquilina K. Endoscopic surgery for intraventricular arachnoid cysts in children: clinical presentation, radiological features, management, and outcomes over a 12-year 
period. Childs Nerv Syst. 2017;34(2):257-66. https://doi.org/10.1007/s003 81-017-3524-9.

3. Klekamp J. A new classification for pathologies of spinal meninges-part 2: primary and secondary intradural arachnoid cysts. Neurosurgery. 2017;81(2): 217-29. https://doi.org/10.1093/neuros/nyx050.

4. Basaldella L, Orvieto E, Tos APD, Barbera MD, Valente M, Longatti P. Causes of arachnoid cyst development and expansion. Neurosurg Focus. 2007;22(2): 1-4. https://doi.org/10.3171/foc.2007.22.2.4.

5. Al-HolouWN YAY, Boomsaad ZE, et al. Prevalence and natural history of arachnoid cysts in children. J Neurosurg Pediatr. 2010;5(6):578-85. https:// doi.org/10.3171/2010.2.PEDS09464.

6. Rao G, Anderson RC, Feldstein NA, Brockmeyer DL. Expansion of arachnoid cysts in children: report of two cases and review of the literature. J Neurosurg. 2005;102(3 Suppl):314-7. https://doi.org/10.3171/ ped.2005.102.3.0314.

7. Weber R, Voit T, Lumenta C, Lenard HG. Spontaneous regressive of a temporal arachnoid cyst. Childs Nerv Syst. 1991;7(7):414-5. https://doi.org/1 $0.1007 / \mathrm{BF} 00304210$

8. Oertel JMK, Wagner W, Mondorf Y, Baldauf J, Schroeder HWS, Gaab MR. Endoscopic treatment of arachnoid cysts: a detailed account of surgical technique and results. Neurosurgery. 2010;67(3):824-36. https://doi.org/1 0.1227/01.NEU.0000377852.75544.E4

9. Choi JU, Kim DS. Pathogenesis of arachnoid cyst: congenital of traumatic? Pediatr Neurosurg. 1998;29(5):260-6. https://doi.org/10.1159/000028733.

10. André A, Zerah M, Roujeau T, et al. Suprasellar arachnoid cysts: toward a new simple classification based on prognosis and treatment modality. Neurosurgery. 2016;78(3):370-80. https://doi.org/10.1227/NEU. 0000000000001049

11. Kim BS, Illes J, Kaplan RT, Reiss A, Atlas SW. Incidental findings on pediatric MR images of the brain. AJNR. 2002;23(10):1674-7.

12. Maixner VJ, Besser M, Johnston IH. Pseudotumor syndrome in treated arachnoid cysts. Childs Nerv Syst. 1992;8(4):207-10. https://doi.org/10.1007/ BF00262847.

13. Weber $\mathrm{F}$, Knopf $\mathrm{H}$. Incidental findings in magnetic resonance imaging of the brains of healthy young men. J Neurol Sci. 2006;240(1-2):81-4. https:// doi.org/10.1016/j.jns.2005.09.008.

14. Crimmins DW, Pierre-Kahn A, Sainte-Rose C, Zerah M. Treatment of suprasellar cysts and patient outcome. J Neurosurg Pediatr. 2006;105(2):10714. https://doi.org/10.3171/ped.2006.105.2.107.

15. Boutarbouch M, Ouahabi El A, Rifi L, et al. Management of intracranial arachnoid cysts: institutional experience with initial 32 cases and review of the literature. Clin Neurol Neurosurg. 2008;1 10(1):1-7. https://doi.org/10.101 6/j.clineuro.2007.08.009

16. Tamburrini G, D'Angelo L, Paternoster G, et al. Endoscopic management of intra and paraventricular CSF cysts. Childs Nerv Syst. 2007;23(6):645-51. https://doi.org/10.1007/s00381-007-0327-4

17. El-Ghandour NMF. Endoscopic treatment of suprasellar arachnoid cysts in children. J Neurosurg Pediatr. 2011;8(1):6-14. https://doi.org/10.3171/2011.4. PEDS1184.

18. Oertel J, Baldauf J, Schroeder HWS, Gaab MR. Endoscopic cystoventriculostomy for paraxial arachnoid cysts. J Neurosurg. 2009;110(4): 792-9. https://doi.org/10.3171/2008.7.JNS0841.

19. Gangemi M, Maiuri F, Colella G, Magro F. Endoscopic treatment of quadrigeminal cistern arachnoid cysts. Minim Invasive Neurosurg. 2005; 48(5):289-92. https://doi.org/10.1055/s-2005-915604.

20. Schroeder HW, Gaab MR, Niendorf WR. Neuroendoscopic approach to arachnoid cysts. J Neurosurg. 1996;85(2):293-8. https://doi.org/10.3171/jns.1 996.85.2.0293.

\section{Publisher's Note}

Springer Nature remains neutral with regard to jurisdictional claims in published maps and institutional affiliations.

\section{Submit your manuscript to a SpringerOpen ${ }^{\circ}$ journal and benefit from:}

- Convenient online submission

- Rigorous peer review

- Open access: articles freely available online

- High visibility within the field

- Retaining the copyright to your article

Submit your next manuscript at $\boldsymbol{\nabla}$ springeropen.com 